\title{
Avaliação do internato médico rural em Medicina de Família e Comunidade da Universidade de Caxias do Sul: reflexões para a educação médica e políticas de saúde
}

\author{
Evaluation of the rural medical internship in Family and \\ Community Medicine at the Universidade de Caxias do Sul: \\ reflections on medical education and health policies
}

\author{
Leonardo Vieira Targa ${ }^{1}$, Tatiana Souza de Camargo ${ }^{2}$
}

\begin{abstract}
Resumo
A educação médica passou por transformações constantes ao longo da História e no Brasil assume características específicas. Recentemente, entre outros aspectos, têm-se debatido sobre a importância da variedade de cenários de ensino e de uma abordagem integral e generalista para o desenho de um perfil de egresso mais próximo às necessidades de saúde da população. Este estudo apresenta uma avaliação qualitativa e quantitativa da experiência de acadêmicos de Medicina, professores e profissionais de saúde envolvidos no internato médico rural em Medicina de Família e Comunidade da Universidade de Caxias do Sul, estado do Rio Grande do Sul, Brasil. Perfis dos participantes, motivadores de estágio, influências sobre opções de trabalho futuro, impacto nas equipes de saúde e aspectos positivos e negativos da experiência são apresentados e discutidos à luz da literatura internacional no tema. $\mathrm{O}$ internato rural aparece como uma experiência positiva na formação médica, com potencial agregador qualitativo para os envolvidos e influência na opção futura de trabalho, ajudando a reduzir a defasagem de recursos humanos em áreas rurais. O diálogo entre as comunidades, equipes de saúde, universidade e gestores locais é essencial para a superação dos desafios cotidianos e para a manutenção das atividades, assim como o suporte institucional aos alunos e qualificação do corpo docente. Sugestões de futuras linhas de pesquisa na área são apresentadas.
\end{abstract}

Palavras-chave: Educação médica; Atenção Primária à Saúde; Medicina de família e comunidade; Áreas rurais; Recursos humanos em saúde.

\footnotetext{
${ }^{1}$ Doutorando em Educação em Ciências: Química da Vida e Saúde na Universidade Federal do Rio Grande do Sul (UFRGS), Porto Alegre, Rio Grande do Sul, Brasil. Professor Assistente de Medicina na Universidade de Caxias do Sul (UCS), Caxias do Sul, Rio Grande do Sul, Brasil. Médico da Família na Prefeitura Municipal de Nova Petrópolis, Rio Grande do Sul, Brasil. E-mail:1vtarga@ucs.br

2 Doutorado em Educação pela Universidade Federal do Rio Grande do Sul, Porto Alegre, Rio Grande do Sul, Brasil. Professora do Departamento de Ensino e Currículo da Faculdade de Educação da Universidade Federal do Rio Grande do Sul, Porto Alegre, Rio Grande do Sul, Brasil.
} 


\begin{abstract}
Medical education has undergone constant transformations throughout history and in Brazil it takes on specific characteristics. Recently, among other aspects, there has been debate about the importance of the variety of teaching scenarios and of an integral and generalist approach to the design of an egress profile closer to the population's health needs. This study presents a qualitative and quantitative evaluation of the experience of medical students, professors and health professionals involved in the rural medical internship in Family and Community Medicine at the Universidade de Caxias do Sul, Rio Grande do Sul state, Brazil. Profile of participants, internship motivators, influences on work options future, impact on health teams and positive and negative aspects of the experience are presented and discussed in the light of international literature on the subject. The rural internship appears as a positive experience in medical training, with qualitative aggregating potential for those involved and influence on the future work option, helping to reduce the gap in human resources in rural areas. Dialogue between communities, health teams, universities and local managers is essential to overcome daily challenges and to maintain activities, as well as institutional support for students and qualification of the teaching staff. Suggestions for future lines of research in the area are presented.
\end{abstract}

Keywords: Medical education; Primary Health Care; Family practice; Rural areas; Human resources in health.

\section{Introdução}

A educação médica passa por transformações constantes ao longo da História e no Brasil assume características específicas. Entre os elementos que recentemente destacam-se, estão a integralidade da formação e a orientação para necessidades locais e comunitárias com busca de um equilíbrio maior entre especialidades e generalismo, inclusive com diversificação de cenários de ensino e uma maior representatividade de atenção ambulatorial. ${ }^{(1)} \mathrm{A}$ responsabilidade social de responder às necessidades das comunidades é o núcleo principal da educação médica rural. A principal razão de ser da educação médica em áreas rurais é desenvolver um número suficiente de médicos rurais devidamente treinados para atender às necessidades das comunidades rurais. ${ }^{(2)}$ Isso ganha especial importância em nosso País, que se propõe a reconhecer a saúde como um direito de todos, que destaca a equidade como princípio doutrinário do Sistema Único de Saúde (SUS), ${ }^{(3)}$ e que apresenta um desequilíbrio importante na distribuição de recursos humanos entre áreas rurais e urbanas.

Um dos aspectos que ganharam grande visibilidade nos últimos anos, inclusive pela criação de políticas específicas, é a relação positiva entre a descentralização da educação médica e o acesso aos serviços de saúde por parte dos usuários. ${ }^{(4)}$ Internacionalmente isso fica evidente pela divulgação cada vez maior dos bons resultados de experiências de currículos descentralizados com desenhos inovadores $^{(5,6)}$ e nacionalmente através da tentativa de diálogo com estas experiências, ${ }^{(7-8)}$ inclusive com a criação de políticas específicas. ${ }^{(9)}$

No Brasil, são relativamente escassas as publicações detalhadas sobre educação médica rural, embora algumas experiências se destaquem. ${ }^{(10-11)}$ Recentemente, foi publicada uma descrição do internato médico rural em Medicina de Família e Comunidade (MFC) da Universidade de Caxias do Sul (UCS), município de Caxias do Sul, estado do Rio Grande do Sul, Brasil. ${ }^{(12)}$ Esse trabalho, ao analisar preliminarmente a experiência e introduzir aspectos relevantes sobre educação médica rural e as políticas de recursos humanos para saúde em nosso País, ressaltou a necessidade de aprofundamento avaliativo. O objetivo do presente estudo é o de suprir esta necessidade de um olhar avaliativo mais complexo sobre este internato médico rural e refletir sobre potenciais desdobramentos.

O internato rural em Medicina de Família e Comunidade da UCS é uma experiência inovadora de educação médica na Atenção Primária à Saúde 
(doravante APS), na qual os alunos dos últimos quatro semestres do curso de Medicina inserem-se em uma Unidade de Saúde da Família (USF) em um município rural na região da Serra Gaúcha, no Rio Grande do Sul, por um período variável, geralmente, de três a cinco semanas. Durante sua participação, eles realizam todas as atividades de um médico de família e comunidade sob supervisão do médico da unidade, com formação especializada em Medicina de Família e Comunidade e que também é professor da UCS. Desde 2007, mais de 550 médicos em formação participaram do estágio, em ao menos um dos quatro municípios participantes. ${ }^{(12)}$

A partir dos resultados expostos neste estudo, serão realizadas comparações com a literatura relacionada ao tema da educação médica rural na graduação, com foco especial para a realidade da América do Sul. Estes resultados podem ser úteis tanto para a criação de experiências semelhantes, quanto para o melhoramento de outros programas já existentes de educação médica fora dos grandes centros urbanos. Procurar-se-á de modo igual analisar o potencial que estas experiências possam ter para as políticas de formação médica e suas implicações para o cuidado da saúde. Os resultados dessas análises também podem ser úteis para comunidades rurais que tenham como objetivo atrair profissionais de saúde. Por fim, inclui-se como objetivo específico a avaliação por parte dos estudantes de um estágio rural e possíveis influências nas opções profissionais posteriores.

\section{Material e Método}

A experiência selecionada para este estudo é a do internato rural em Medicina de Família e Comunidade da Universidade de Caxias do Sul a partir de uma amostra de um dos quatro municípios participantes: o de Nova Petrópolis, no Rio Grande do Sul. ${ }^{(12)}$ Nesta etapa do estudo avaliativo, os alunos que estagiaram na Unidade Básica de Saúde (UBS) do Pinhal Alto, nos últimos dois anos (correspondente a 2018 e $2019, \mathrm{n}=42$ ) foram convidados, via correio eletrônico, em fevereiro de 2020, a responder questionários autoaplicados (Anexo 1), com perguntas abertas e fechadas. Os alunos das próximas rotações $(n=13)$ foram convidados pessoalmente, após o final do estágio, a responder os mesmos questionários. A amostra total foi de 55 estudantes, dos quais 49 efetivamente participaram (89,09\%). Os questionários foram respondidos de forma anônima, com utilização do Google Forms. O tamanho final da amostra foi determinado por conveniência.

Os membros da mesma equipe $(\mathrm{n}=8)$ foram convidados a responder questionários autoaplicados, individuais, impressos, anônimos, após uma reunião de equipe (Anexo 2), ocorrida no primeiro semestre de 2020. A equipe participante é composta, além do médico que é o pesquisador, e que não respondeu o questionário, por uma enfermeira, duas técnicas de enfermagem e cinco agentes comunitárias de saúde do sexo feminino. Os quatro médicos de família das unidades de saúde que recebem os alunos, e que também são professores da UCS, responderam questionários autoaplicados via plataforma Google Forms, em fevereiro e março de 2020 .

As respostas abertas foram tabuladas com uso do software Microsoft ${ }^{\circledR}$ Excel $^{\circledR}$ e agrupadas em termos de semelhança de temática para serem posteriormente analisadas, comparadas com a literatura internacional e apresentadas em termos de frequência de aparecimento. O mesmo aplicativo foi usado para gerar gráficos de respostas. Este trabalho é um recorte de um estudo mais amplo, relacionado à tese de doutorado no tema. Nesta etapa a análise qualitativa foi usada de forma complementar à quantitativa, em um único plano. Outra etapa qualitativa mais aprofundada envolvendo o uso da Teoria do Ator-Rede está em andamento e será publicada futuramente.

Todos os participantes foram esclarecidos verbalmente e receberam por escrito orientações a respeito do projeto, conforme os moldes internacionalmente recomendados de pesquisa. $\mathrm{O}$ consentimento informado foi obtido. A Universidade de Caixas do Sul manifestou concordância com 
o Termo de Consentimento Livre e Esclarecido (TCLE) e o projeto foi aprovado nos Comitês de Ética em Pesquisa (CEP) da Universidade Federal do Rio Grande do Sul (UFRGS), em Porto Alegre, Rio Grande do Sul e da Universidade de Caxias do Sul (UCS), registrado sob o número do CAAE: 22429219.0.3001.5341.

\section{Resultados e Discussão}

A análise das respostas nos permite fazer algumas reflexões interessantes à discussão geral de educação médica e mais especificamente às práticas educativas que ocorrem fora de grandes centros urbanos e em ambiente diverso do hospital universitário - onde comumente se dá grande parte da formação dos profissionais de saúde.

\section{Sexo}

Dos alunos respondentes aos questionários, 34 se declararam mulheres $(69,4 \%)$ e $15(30,6 \%)$, homens (vide Figura 1). Os dados de gênero, que mostram uma predominância do sexo feminino, são compatíveis com o perfil de alunos da UCS e estão de acordo com tendências de feminização do curso de Medicina. ${ }^{(13)}$ Esta presença crescente também se reflete no perfil de médicos no interior e o oferecimento de experiências de práticas médicas rurais para as estudantes em formação está em conformidade com as recomendações nacionais ${ }^{(14)}$ e internacionais de experts. ${ }^{(15)}$ Entre os professores ocorre o inverso: a maioria ( $75 \%$ ) é do sexo masculino, o que possivelmente reflete a relativa juventude das alterações demográficas citadas.

Figura 1 - Distribuição do sexo relatado pelos alunos (esquerda) e professores (direita).

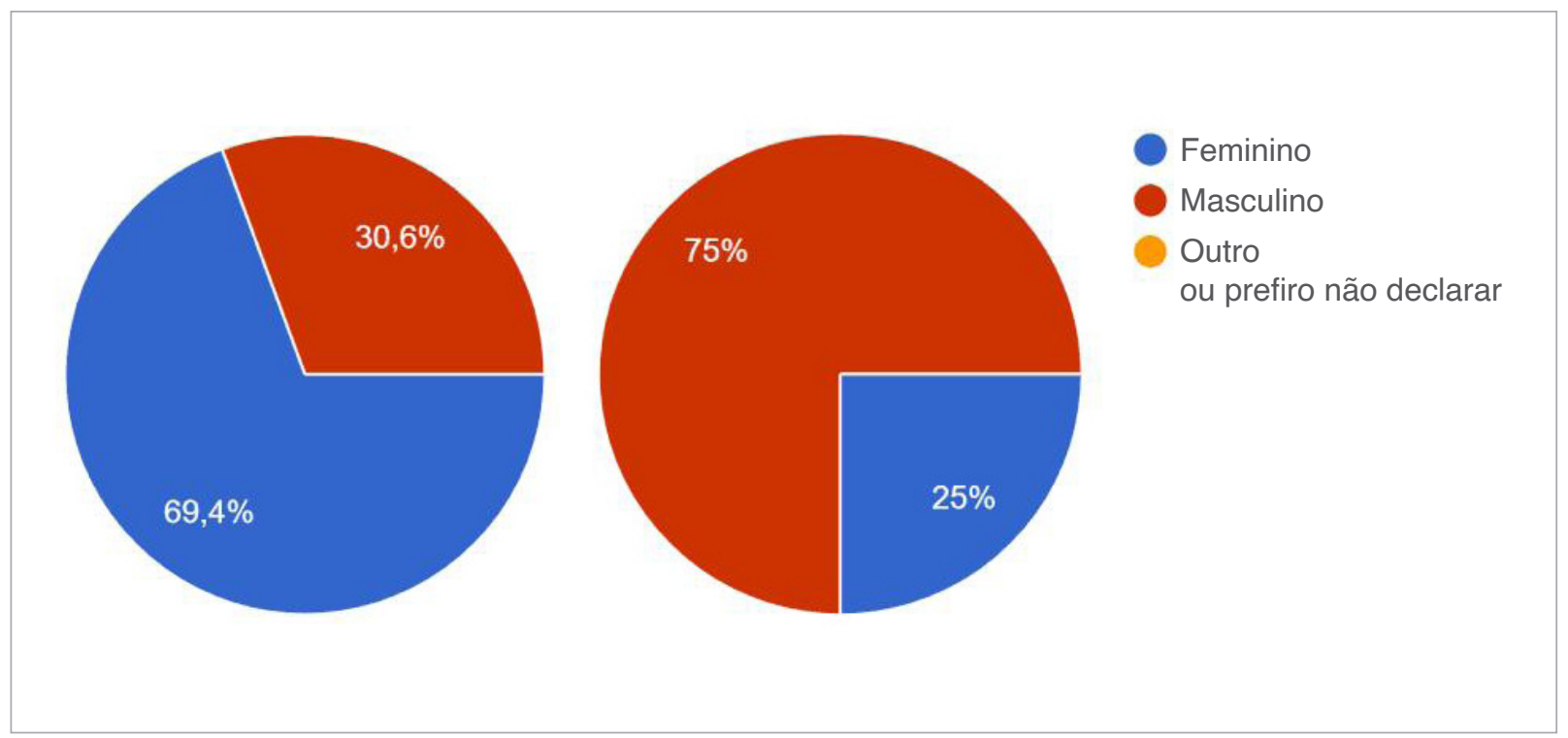

Fonte: os autores.

\section{Local de nascimento e formação}

A origem rural ou urbana dos estudantes, bem como o local predominante em sua educação básica e média estão apresentados nas Figuras $2 \mathrm{e}$ 3. Fica evidente a majoritária origem urbana dos estudantes de Medicina da Universidade de Caxias do Sul (conforme Figura 2), o que é compatível com estudos realizados alhures, ${ }^{(16-17)}$ mas que não se constitui unanimidade. ${ }^{(18)}$ Isso é relevante em termos de possibilidade futura de trabalho em áreas rurais, visto que vários estudos ${ }^{(19-20)}$ demonstram ligação com uma origem rural, alguns mostrando de 4 a 10 vezes mais probabilidade. ${ }^{(21)} \mathrm{O}$ mesmo pode ser constatado em relação à formação predominante urbana dos professores (Figura 3). 
Figura 2 - Distribuição das características do local de nascimento dos alunos (esquerda) e professores (direita).

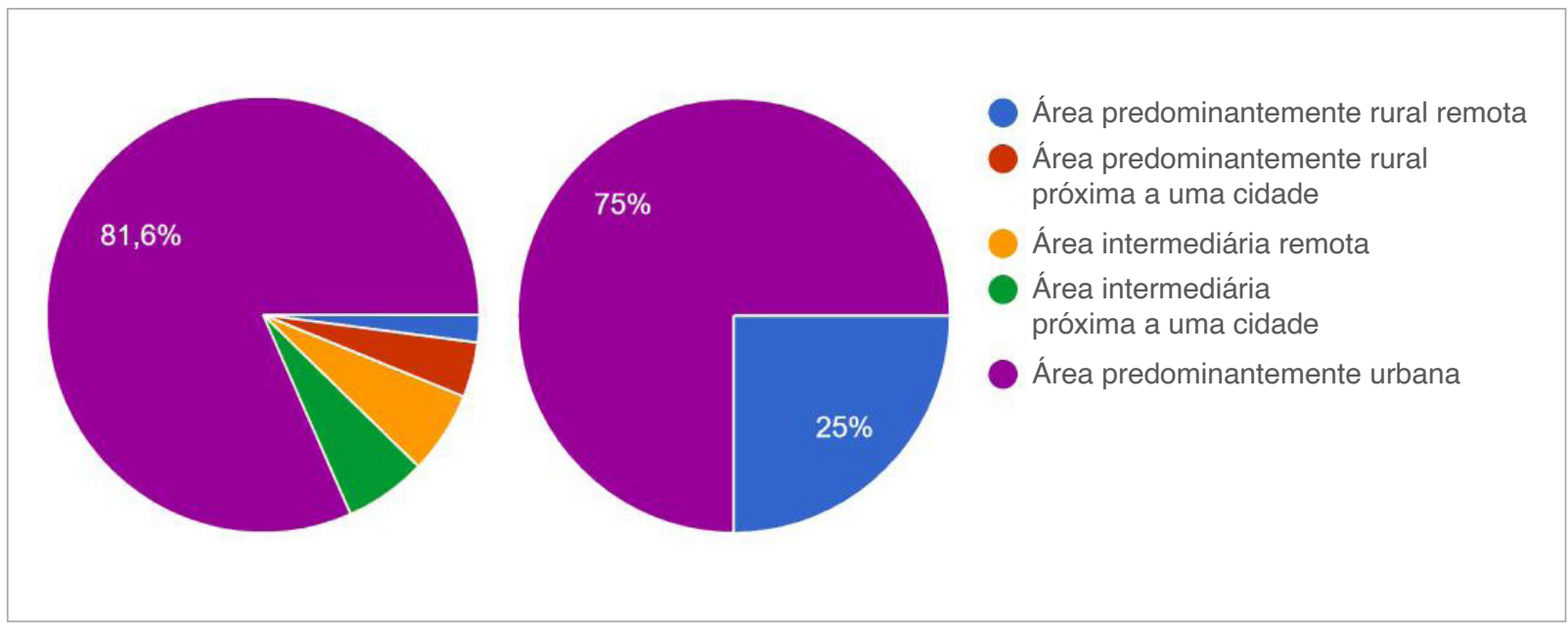

Fonte: os autores.

Figura 3 - Características do local de formação predominante (ensino básico e médio) para alunos (esquerda) e professores (direita).

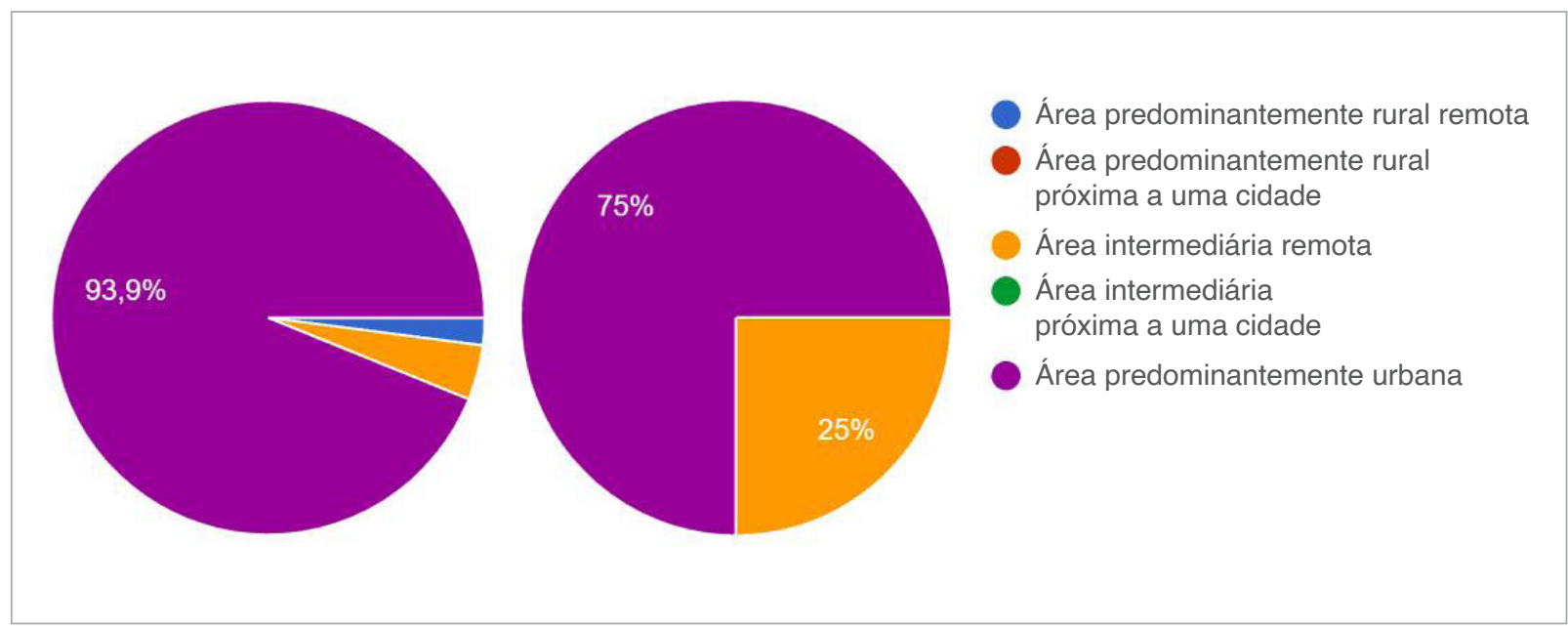

Fonte: os autores.

Motivação inicial e após o estágio rural para trabalhar como médico (a) fora de um grande centro urbano

Ao avaliar a expectativa de trabalho fora de uma grande cidade antes e depois do estágio rural, percebe-se que a maioria dos estudantes relata um atrativo médio a baixo, no momento da aprovação para o curso de Medicina. Estes dados estão de acordo com os de outros países da América do Sul, onde a probabilidade dos estudantes de Medicina irem para o meio rural é, em geral, baixa. Esta chance varia entre países, sendo melhor no Chile, Colômbia e Paraguai, ${ }^{(22-23)}$ alguns deles aparentemente por direcionarem políticas específicas combinadas para atenção primária em áreas rurais. No Chile, mais da metade das universidades adotaram internatos rurais ${ }^{(22)}$ que depois pontuam para serviço rural compulsório. No Brasil, movimentos similares foram tentados nos últimos anos, ${ }^{(24)}$ mas não foram encontrados resultados na literatura em relação ao desejo dos estudantes em aderir a estas 
políticas e também não tem havido continuidade destas políticas. A visão negativa em relação à APS e ao trabalho em áreas rurais tem sido pior, a partir da literatura, no Uruguai, ${ }^{(25)}$ na Venezuela ${ }^{(26)}$ e no Peru. ${ }^{(23,27)} \mathrm{Na}$ Argentina, menos de um quarto dos estudantes tem convicção que o meio acadêmico estimula a ida para áreas rurais e pobres e aproximadamente $6 \%$ referem que percebem uma ação do governo neste sentido. Aproximadamente um terço dos estudantes considera trabalhar nas áreas rurais neste país. ${ }^{(28)}$ No Peru, os estudantes de medicina parecem ter menos vocação rural, ${ }^{(29)}$ sendo esta melhor com enfermagem, em um estudo, mas semelhante $(25 \%)$ em outro. ${ }^{(30-31)}$ Outro estudo do
Peru ${ }^{(27)}$ confirma baixa expectativa de trabalho no interior $(7 \%)$ e ainda pior em meio rural $(0,5 \%)$.

Ao final do estágio rural, no entanto, uma mudança é perceptível, com a maioria dos alunos referindo uma vontade alta ou altíssima somando mais do que o dobro (de 30,6\% para 77,5\%) das respostas de início de curso (ver Tabela 1). De forma similar, a proporção de alunos que referiu uma probabilidade baixa ou baixíssima caiu expressivamente (de 40,8\% para 6,1\%). A opção preferencial por trabalhar fora de um grande centro também dobrou. Em outro momento do questionário, 89,7\% dos alunos referiram que sua chance de trabalhar neste tipo de ambiente aumentou após o estágio.

Tabela 1 - Motivação inicial e final dos alunos para trabalhar fora de um grande centro urbano.

\section{Grau de motivação}

Baixíssima (não pensou, ou pensava muito negativamente).

Baixa (não gostaria; ou pensava negativamente em relação à opção).

Média (pensava como última opção).

Alta (pensava, mas não estava certo; ou era plano secundário).

Altíssima (era seu plano preferencial).

\section{No início do curso Após estágio rural}

$\begin{array}{cc}6(12,2 \%) & 1(2 \%) \\ 14(28,6 \%) & 2(4,1 \%) \\ 14(28,6 \%) & 8(16,3 \%) \\ 11(22,4 \%) & 30(61,2 \%) \\ 4(8,2 \%) & 8(16,3 \%)\end{array}$

Fonte: os autores.

Estes achados parecem ser compatíveis com estudos internacionais que mostram um aumento da probabilidade de recrutamento rural para profissionais que tiveram parte de sua formação médica fora de um grande centro urbano. ${ }^{(20-21,32-33)}$ Este efeito parece impactar a visão a respeito da saúde das populações rurais, mesmo que o aluno posteriormente não opte pelo trabalho em área rural diretamente. Este efeito parece persistir por longo prazo. ${ }^{(34)}$

Algumas limitações podem ser discutidas a partir disso. Um potencial viés de confusão pouco comentado pode estar presente ao menos em alguns destes estudos. É possível, em estágios opcionais - como é o de Caxias do Sul -, que tanto uma experiência rural aumente a probabilidade de trabalho posterior com comunidades rurais, quanto o contrário, que ter uma origem rural e previamente um desejo de trabalho nestas áreas aumente a procura por estas experiências de ensino. ${ }^{(35)}$ Neste trabalho este problema foi evitado parcialmente pela técnica de questionamento em dois momentos mas apresenta uma limitação típica de estudos retrospectivos: o viés de memória, que é a tendência de indivíduos terem suas recordações de acontecimentos passados afetadas pela exposição a eventos presentes.

Dos alunos que relataram uma origem não predominante urbana $(\mathrm{n}=9,18,3 \%$, sendo quatro mulheres e cinco homens), somente um (11\%) relatou motivação baixa, e nenhum baixíssima, para trabalho fora de um grande centro urbano ao entrar no curso de Medicina, contra quase metade (47,5\%) dos alunos de origem predominantemente urbana. 
Por outro lado, três deles $(33 \%$ dos de origem não predominantemente urbana) reportaram motivação alta ou altíssima no início do curso, em comparação com $12(30 \%)$ de seus colegas de origem predominante urbana. Isso mostra que, em geral, os alunos que nasceram fora de grandes centros urbanos entram na faculdade com uma disposição maior para o trabalho nestas áreas, embora, por serem relativamente poucos, ainda são minoria em termos de motivação alta para este tipo de trabalho.

Em relação ao sexo, $26 \%$ das estudantes mulheres relataram ter entrado com motivação alta ou altíssima no curso para trabalho fora de grandes centros urbanos em comparação com $40 \%$ dos homens, e $44 \%$ com motivação baixa ou baixíssima contra $33 \%$ dos homens. Isso demonstra que o trabalho em grandes centros urbanos parece ser mais atraente ao início do curso para as mulheres, mas a maioria está disposta a repensar esta probabilidade até o final do curso, possivelmente influenciados pelo estágio rural. Para avaliar melhor o grau de influência direta do estágio seria interessante incluirse um grupo controle de alunos que não realizaram nenhuma rotação rural. No caso dos professores, apenas uma professora de origem predominantemente urbana citou que não teve motivação para o trabalho fora dos grandes centros ao entrar no curso de Medicina. Todos os professores homens, e somente eles, relataram ter tido ao menos uma experiência no meio rural durante a residência, de forma optativa. Todo o grupo de professores participantes relatou como altíssima a vontade atual de permanecer no interior.

Em relação à origem, para 55,5\% dos alunos provenientes de áreas não predominantemente urbanas, a probabilidade de trabalhar fora de um grande centro aumentou após o estágio rural, em comparação com $62,5 \%$ dos de origem urbana. As três estudantes que relataram diminuição da probabilidade eram mulheres de origem predominante urbana. Nenhum estudante do sexo masculino ou de origem não predominante urbana relatou diminuição da probabilidade desde o início do curso. É possível que em países como o Brasil, onde a maioria dos médicos vem de áreas urbanas, estes ainda constituam a maior parte dos profissionais que atendam áreas rurais, proporcionalmente. $\mathrm{O}$ mesmo ocorrendo em países com mais tradição em saúde rural, como demonstrado no Canadá. ${ }^{(20)}$ Alguns autores sugerem que os efeitos positivos de experiências de educação médica em áreas rurais sejam mais influentes ao longo do curso para estes alunos, de origem urbana, do que para os de origem rural, o que parece compatível com os resultados aqui encontrados. ${ }^{(20,35)}$ Isso demonstra a importância de não se abandonar as políticas de recrutamento e retenção de profissionais que combinam múltiplas estratégias conforme recomenda a literatura, ${ }^{(2,4,33)}$ em prol de abordagens simplificadas, como as de estímulo ao ingresso universitário isoladamente.

Outro aspecto relevante para países como o Brasil, com índices ruins de educação básica, é que investir-se exclusivamente em reserva de cotas para estudantes rurais pode não garantir uma melhor representatividade, visto que diversos obstáculos são descritos, não só educacionais, como financeiros e de adaptação. ${ }^{(36)} \mathrm{A}$ discussão mais ampla de políticas afirmativas é complexa e foge ao escopo deste trabalho.

Da mesma forma, a abertura indiscriminada de novos cursos de Medicina descentralizados sem a devida preocupação com estrutura e qualidade de docência, em locais onde o sistema de saúde apresenta deficiências importantes, pode não ter o mesmo impacto - ou até ter o resultado inverso de outras realidades, limitando a aplicabilidade local de evidências internacionais. Embora a origem rural e oportunidade de treinamento em área rural estejam relacionadas com opção futura de trabalho rural, estes não são os únicos fatores que influenciam esta decisão, e as práticas e políticas de recursos humanos em saúde para estas comunidades devem levar em conta outros aspectos, tais como as condições de exercer a profissão com qualidade, opções de trabalho e lazer para a família e remuneração adequada. ${ }^{(4,37)}$

Apesar destas limitações, devido ao importante volume de evidências e ao razoável consenso entre os experts, é altamente provável que exista 
realmente relação entre estes fatores e devem ser levadas em consideração na construção de estratégias e políticas de recursos humanos em saúde para áreas rurais. Uma combinação de aspectos prévios e estímulos durante a formação médica, conhecidos internacionalmente como "nature and nurture" (natureza e nutrição) ${ }^{(38)}$ parece ser a forma mais desejável de encararmos o quadro mais amplo.

\section{Motivadores para trabalho fora ou em um grande centro urbano}

Os principais motivadores citados pelos estudantes para futuramente optarem pelo trabalho fora de uma grande cidade são, em ordem decrescente: a qualidade de vida; aspectos relacionados à qualidade do trabalho; aspectos financeiros e de mercado de trabalho e, por último, a preferência pessoal subjetiva. Em relação à qualidade de vida, muitos estudantes não aprofundaram os motivos, mas quando o fazem, são citados principalmente aspectos familiares, de deslocamento e trânsito facilitado e de segurança (ver Tabela 2). Os mesmos fatores são citados pelos professores, para se manterem no interior, sendo que nenhum citou outros fatores. Quando aprofundam aspectos relacionados à qualidade do trabalho, são citados pelos alunos (em ordem de frequência em que aparecem) a continuidade do cuidado, o senso de comunidade e o conhecimento do contexto de vida do paciente, o desejo de ganhar experiência profissional, o desejo de ser valorizado profissionalmente e a qualidade da relação com os pacientes. Estes achados são compatíveis com os de outros trabalhos. ${ }^{(39)}$

Tabela 2 - Motivadores atuais entre alunos para trabalhar fora de um grande centro urbano.

\begin{tabular}{lc}
\hline Motivação & $\mathbf{n}$ \\
\hline Qualidade de vida & $\mathbf{1 9}(\mathbf{3 8 , 7 \% )}$ \\
Qualidade de vida & $12(24,4 \%)$ \\
Aspectos familiares & $4(8,2 \%)$ \\
Fugir do trânsito / deslocamento & $2(4,1 \%)$ \\
Segurança & $1(2 \%)$ \\
Aspectos relacionados à qualidade do trabalho & $\mathbf{1 2}(\mathbf{2 4 , 4 \% )}$ \\
Continuidade do cuidado & $6(12,2 \%)$ \\
Conhecer o contexto do paciente e senso de comunidade & $4(8,2 \%)$ \\
Ser valorizado profissionalmente (não financeiramente) & $2(4,1 \%)$ \\
Aspectos financeiros e de mercado de trabalho & $\mathbf{1 0}(\mathbf{2 0 , 4 \% )}$ \\
Ganhar experiência profissional & $\mathbf{2 ( 4 , 1 \% )}$ \\
Preferência subjetiva / pessoal & $\mathbf{2 ( 4 , 1 \% )}$ \\
\hline
\end{tabular}

Fonte: os autores.

Quando questionados sobre motivadores que os levariam a preferir trabalhar em grandes centros urbanos (ver Tabela 3), as principais motivações citadas são as relacionadas a aspectos profissionais, em especial o pertencimento a um "serviço especializado" e "de referência", facilidade de acesso para encaminhar pacientes a colegas, acesso facilitado a exames e trabalho em ambiente hospitalar.
Segue a isso, fatores relacionados a estilo de vida com opções de lazer sendo o item mais citado, seguido de proximidade com a família. A seguir, têm-se os argumentos financeiros, que aparecem menos do que nas respostas de motivadores rurais, empatados com ter acesso a mais oportunidades de trabalho. Menos referidos, mas também importantes, são o acesso à escola para filhos, preferência 
pessoal e oportunidades de aprimoramento nos estudos posteriormente à graduação.

É interessante perceber como os motivadores dos estudantes são semelhantes, somente invertendo-se em importância, relacionando interior com qualidade de vida, primeiramente, e aspectos profissionais, principalmente com zonas urbanas. Os aspectos financeiros e de mercado de trabalho, os quais são pontos destacados pela Organização Mundial da Saúde (OMS) ${ }^{(4)}$ para atração de recursos humanos, podem refletir o estado supersaturado do mercado de trabalho médico em grandes cidades $^{(13)}$ e podem estar relacionados às políticas recentes em nosso País, de estímulo à interiorização. Há alguma evidência de um possível efeito de "transbordamento para o interior", ao se formar mais médicos, independente de sua opção inicial para o trabalho rural, que pode estar relacionado também a isso. ${ }^{(40)}$

Um campo de estudo potencial interessante é a expectativa de tempo de trabalho no rural previsto para os estudantes que admitem esta possibilidade futura, ${ }^{(41)}$ além de quais fatores que contribuiriam mais para a retenção a longo prazo, enquanto aqui parece estarmos lidando mais com a possibilidade de recrutamento. De qualquer forma, chama a atenção a relativa variedade de motivações entre os alunos, dando razão às recomendações de investirse em múltiplas estratégias também para ampliar a variedade de profissionais. ${ }^{(37)}$

Tabela 3 - Motivadores entre alunos para trabalho urbano.

\section{Motivação}

Aspectos Profissionais

Vontade de trabalhar em serviço especializado / de referência

Maior facilidade para encaminhamentos, exames, consultorias

Vontade de trabalhar em hospital

Oportunidades de carreira / de ampliação de estudo

\section{Qualidade de vida}

Opções de lazer

Proximidade da família

Escola para família

Proximidade da população

Financeiro / oportunidades de mercado de trabalho

Preferência pessoal n

$34(69,4 \%)$

$16(32,6 \%)$

$12(24,4 \%)$

$5(10,2 \%)$

$2(4,1 \%)$

$13(26,5 \%)$

$7(14,2 \%)$

$4(8,2 \%)$

$1(2 \%)$

$1(2 \%)$

$5(10,2 \%)$

$2(4,1 \%)$

Fonte: os autores.

Para os professores, embora relatem altíssima probabilidade de manterem-se em áreas rurais, como visto acima, são citados como possíveis motivadores para uma mudança mais urbana o contato com uma maior rede de serviços disponíveis, proximidade com a família, ter contato com realidades populacionais mais variadas (diferentes origens e culturas, em comparação com a relativa homogeneidade dos locais do interior onde ocorre o estágio rural) e oportunidades de pesquisa. Alguns destes motivadores podem ser lidos de forma inversa, constituindo-se importantes indicadores de fatores que ajudariam a fixar os profissionais no interior. Sendo assim, políticas e estratégias que ajudem a proximidade com a família e engajamento em projetos de pesquisa seriam exemplos de potenciais ações para combater a migração dos profissionais que já estão no interior. 


\section{Motivadores para escolher fazer}

o estágio rural

Ao serem questionados sobre os motivos pelos quais se optou por fazer o estágio rural, mais frequentemente é citada a vontade de realizar a experiência, em geral. Estão incluídos neste item falas como: vontade de experimentar "uma aventura"; se experimentar "em um cenário ou realidade diferente"; curiosidade; ou ainda, ter contato com uma cultura diferente. Após este motivador principal, surgem as motivações relacionadas ao desejo de formação complementar, referindo especificamente as características da APS, da MFC ou no sentido de uma prática generalista. Exemplos são o desejo de atender na porta de entrada do sistema de saúde; experimentar a longitudinalidade do cuidado; ter contato com o contexto do paciente; e em relação ao escopo mais amplo de habilidades necessárias à prática da medicina geral, em área rural. Logo a seguir, aparece o relato positivo de colegas como motivador e, após, o desejo de formação complementar. Esta última se expressa especificamente citando-se o mercado de trabalho posterior à formação. Menos frequentes, mas ainda relevantes, são a identificação pessoal com o meio rural e o interior; gostar de medicina rural; e o contato prévio positivo com os professores (Tabela 4). Estes motivadores estão de acordo com estudos de países do nosso continente, onde frequentemente aparecem como vantagens da educação médica rural $^{(42-44)}$ e seu mapeamento pode ser útil especialmente para experiências novas que buscam atrair os estudantes.

Tabela 4 - Motivação entre alunos para realizar estágio rural.

\section{Motivação}

Experimentar-se em uma realidade diferente, curiosidade.

Desejo de formação complementar citando especificamente as características da APS ou da MFC/prática generalista.

Relato positivo de colegas em relação à qualidade do estágio.

Desejo de formação complementar citando mercado de trabalho posterior.

Identificação pessoal com meio rural e/ou com medicina rural.

Contato prévio positivo com os professores.
$29(59,1 \%)$

$18(36,7 \%)$

$8(16,3 \%)$

$7(14,2 \%)$

$2(4,1 \%)$

$1(2 \%)$

Fonte: os autores.

Aspectos que mais apreciou durante o estágio

Em relação aos aspectos valorizados pelos estudantes durante o estágio, os itens mais citados (ver Tabela 5) são os relacionados à qualidade do serviço. Isso inclui em ordem decrescente a competência para resolver os problemas dos pacientes, a longitudinalidade do cuidado, a proximidade ou vínculo com a comunidade, a abordagem familiar e centrada na pessoa, a integralidade do cuidado, a relação da equipe de saúde com a população e a importância dada à prevenção. São ainda citados a organização, a dinâmica de atendimento, rapidez nos exames, multidisciplinaridade, estrutura física adequada, competência cultural da equipe, tempo de atendimento e enxergar na prática os princípios da APS. A qualidade do trabalho da equipe que recebe os estudantes, bem como do sistema de saúde local e de sua articulação com o sistema mais amplo parecem importantes e estão relacionados com os resultados positivos anteriormente citados de aumento de motivação de trabalho nestas áreas. ${ }^{(23-24)}$ Além da importância disto ser destacada na literatura sobre o assunto, é reforçada indiretamente por 
relatos de experiências onde isso não ocorre, resultando em impacto negativo. ${ }^{(45)}$ Mesmo estágios curtos, porém com qualidade, parecem influenciar escolhas de carreira. ${ }^{(2,46)}$

As características do trabalho no interior como o relativo isolamento e o tamanho menor das equipes muitas vezes estimulam uma maior resolutividade e ampliação das ações realizadas em comparação com unidades de saúde urbanas. ${ }^{(47)}$ Outros dos diferenciais destacados desta experiência são a longitudinalidade (alguns professores são médicos há mais de dez anos na mesma unidade) e a formação específica dos professores em MFC. Além disso, a atuação docente é voluntária e valorizada pelas instituições, visto que agrega trabalho extra, exige competências e apresenta desafios diferentes do que a assistência isolada. ${ }^{(48)}$

O contato com a medicina de família e comunidade enquanto área de atuação e especialidade, como prática generalista ("todas especialidades numa só" como diz um aluno), é também citado especificamente, com certa frequência. Isso parece demonstrar que ao menos para alguns alunos, ao longo do estágio, surgem oportunidades de refletir sobre a pressão por especialização existente e a confrontar alguns mitos como o de que é muito difícil fazer medicina generalista de boa qualidade. Os médicos de família são médicos generalistas especializados na promoção de saúde e na prevenção, diagnóstico e tratamento dos problemas mais frequentes, a partir de uma abordagem centrada na pessoa e seu contexto familiar e comunitário. Ao estar inserido longitudinalmente em uma comunidade, há condições privilegiadas para proporcionar ao estudante um melhor entendimento do processo saúde-doença e do cuidado integral da saúde a partir de um entendimento amplo dos determinantes de saúde sem descuidar da excelência científica clínica. $^{(49-50)}$ Além destes fatores relacionados com a qualidade do serviço, surgem a seguir a variedade de motivos de consulta, bem como de grupos de pacientes atendidos (alta representatividade populacional, como adultos, idosos, crianças e gestantes). A qualidade de vida e tranquilidade do ambiente aparecem a seguir, seguidas do relacionamento positivo com os professores, a relação de liberdade para elaborar e expor planos de conduta e raciocínios clínicos. Ainda em relação aos aspectos relacionados ao ensino, são destacados pelos alunos o incentivo e apoio logístico do preceptor ao estudo, a abordagem baseada em evidência e o tempo para estudar.

Seguem após, a qualidade do acolhimento da comunidade e o respeito ao médico, bem como a sensação de fazer parte de uma comunidade, diferente da experiência em grandes centros urbanos, segundo os alunos. A relação positiva com a equipe de saúde aparece a seguir. Estes dois aspectos positivos citados reforçam o envolvimento da comunidade e da equipe na proposta de parceria entre a Universidade de Caxias do Sul e o sistema de saúde local. Estes são apontados como essenciais na construção e manutenção de experiências de ensino rural para uma maior equidade em saúde. ${ }^{(49)}$

As visitas domiciliares são citadas a seguir, e são um dos diferenciais importantes dos estágios hospitalares. São também momentos especiais para que vários dos outros fatores citados apareçam e sejam mais facilmente experimentados pelos estudantes em contato com a equipe. Constitui-se também espaço para outro aspecto aparecer que é o treinamento da adaptação das competências aos recursos disponíveis, visto que não há, em geral, acesso fácil a certos recursos tecnológicos que se dispõem usualmente no hospital escola, aprendendo a "resolver os problemas mais prevalentes" com os "recursos disponíveis" e fazer "uma medicina simples e eficiente". É interessante perceber como os estudantes muitas vezes são surpreendidos pela real prevalência dos agravos em uma população qualquer, visto que não há a usual pré-seleção de casos graves com os quais costumam se deparar nos estágios especializados. Tendo isto em vista, frequentemente se dão conta de como a maioria dos casos de saúde são facilmente manejados com recursos relativamente simples e reforçam conhecimentos de semiologia médica, relações pessoais, comunicação interpessoal e epidemiologia, entre outros. 
Tabela 5 - Aspectos do estágio citados como preferidos pelos alunos.

\begin{tabular}{lc}
\hline Aspecto citado como preferido & n (alunos) \\
\hline Qualidade do serviço & $\mathbf{4 6}(\mathbf{9 3 , 8 \% )}$ \\
Competência do serviço / grau de resolutividade dos problemas & $21(42,8 \%)$ \\
Enxergar os princípios da APS & $26(53 \%)$ \\
Longitudinalidade do cuidado & $12(24,4 \%)$ \\
Integralidade & $4(8,2 \%)$ \\
Coordenação & $1(2 \%)$ \\
Competência cultural & $4(8,2 \%)$ \\
Abordagem familiar e centrada na pessoa & $8(16,3 \%)$ \\
Abordagem centrada na comunidade & $17(34,6 \%)$ \\
Vínculo com a comunidade & $17(34,6 \%)$ \\
Visão do contexto & $5(10,2 \%)$ \\
Variedade de motivos de atendimento e representatividade populacional & $6(12,2 \%)$ \\
Contato com a medicina de família e comunidade, prática generalista & $3(6,1 \%)$ \\
Importância da prevenção e educação em saúde & $2(4,2 \%)$ \\
Multidisciplinaridade & $1(2 \%)$ \\
Qualidade de vida & $\mathbf{5 ( 1 0 , 2 \% )}$ \\
Acolhimento da comunidade & $\mathbf{5 ( 1 0 , 2 \% )}$ \\
Aspectos relacionados ao ensino & $\mathbf{5 ( 1 0 , 2 \% )}$ \\
Tempo para estudar & $\mathbf{4 ( 8 , 2 \% )}$ \\
Relação da equipe com o estudante & $\mathbf{3 ( 6 , 1 \% )}$ \\
Aprender a trabalhar com os recursos disponíveis & $\mathbf{2 ( 4 , 1 \% )}$ \\
Visitas domiciliares & $\mathbf{2 ( 4 , 1 \% )}$ \\
\hline
\end{tabular}

Fonte: os autores.

\section{Aspectos do estágio menos apreciados pelos alunos}

Em relação ao que gostaram menos (Tabela 6), aparecem em primeiro lugar os fatores relacionados ao deslocamento até a UCS (mas menos citados as dificuldades de acesso para alimentação, o deslocamento até Caxias do Sul para as aulas teóricas semanais e as dificuldades de comunicação, uma vez que alguns lugares podem apresentar problemas para o acesso à rede de telefonia celular e qualidade de sinal de internet). A frequência com que estes aspectos aparecem, parece reforçar as recomendações internacionais de apoio institucional aos estudantes, sobretudo de regiões menos favorecidas. ${ }^{(49)}$ Neste caso específico, a Universidade oferece a todos os estagiários que vão aos municípios do interior um valor que cobre os principais gastos de estadia e deslocamento.

Eventuais dificuldades de acesso a recursos terapêuticos e diagnósticos, sejam por tempo, burocracia ou mesmo ausência, são os itens a seguir mais citados, incluindo exames, encaminhamentos para referência especializada e para hospitalização e material para realização de pequenos procedimentos, nesta ordem. Sensação de isolamento e estar no meio rural foram problemas citados por quatro alunos, seguidos por dificuldades de comunicação com pacientes (especialmente citados pacientes idosos que não falavam bem o português) e mudanças de estilo de vida (não especificadas, mas provavelmente relacionadas aos itens acima citados 
com estar no meio rural). Dois alunos citaram o de revisar conteúdos e indisponibilidade de rounds pouco tempo de estágio como um fator importante. de discussão sobre os casos. Também apareceram Todas as outras respostas apareceram somente uma de forma pontual não gostar de atender casos de vez, sendo as seguintes: insetos, excesso de visi- Covid-19 (provavelmente durante o início da pantas domiciliares no final da tarde em um local de demia) e em relação à qualidade das acomodações. estágio, incompreensão dos pacientes em serem atendidos por alunos, dificuldade de comunicação com paciente por "nível social baixo", dificuldade Estes fatores citados são semelhantes aos normalmente identificados na literatura como obstáculos à prática rural. ${ }^{(2,41)}$

Tabela 6 - Aspectos citados como menos apreciados pelos alunos.

\begin{tabular}{lc}
\hline Aspecto & $\mathbf{n}$ \\
\hline Deslocamento & $\mathbf{1 6}(\mathbf{3 2 , 6 \% )}$ \\
Para a Unidade Básica de Saúde & 14 \\
Para aula teórica na UCS & 1 \\
Para alimentação no dia a dia & 1 \\
Dificuldades no trabalho & $\mathbf{9 ( 1 8 , 3 \% )}$ \\
Para conseguir exames & 3 \\
Para hospitalização de pacientes & 2 \\
Para encaminhar para especialistas & 2 \\
Para realização de pequenos procedimentos & 1 \\
Para receber o retorno de uma hospitalização (contrarreferência) & 1 \\
Nada & $\mathbf{7 ( 1 4 , 2 \% )}$ \\
Dificuldades de comunicação & $\mathbf{4 ( 8 , 2 \% )}$ \\
Com idosos devido ao idioma & 3 \\
Com pacientes de nível educacional baixo & 1 \\
Sensação de isolamento & $\mathbf{3 ( 6 , 1 \% )}$ \\
Horários de atividades & $\mathbf{2 ( 4 , 2 \% )}$ \\
Horário engessado & 1 \\
Das visitas domiciliares & 1 \\
Pouco tempo de estágio & $\mathbf{2}$ \\
Características dos motivos de consulta & $\mathbf{4 , 2 \% )}$ \\
Pouca diversidade & $\mathbf{2 ( 4 , 2 \% )}$ \\
Pouca complexidade & 1 \\
Olteração de rotina de vida & 1 \\
\hline
\end{tabular}

Fonte: os autores.

Alguns autores ${ }^{(2)}$ chamam a atenção para o fato de que as mesmas características que são estimulantes para uns em relação ao isolamento do meio rural, podem ser desestimulantes para outros. De maneira semelhante, os aspectos culturais são estimulantes e interessantes para uns, mas ao mesmo tempo dificultam a comunicação médicopaciente com consequências potenciais tanto para o cuidado do paciente quanto para os desfechos educacionais. 
Benefícios ou prejuizos percebidos no estágio rural e possibilidade de recomendá-lo

No que se refere à sensação de benefício ou prejuízo quanto à formação pessoal e profissional, somente um aluno deu uma resposta neutra ou indiferente, sendo todas as outras positivas em relação à opção de ter realizado estágio rural. A maioria das respostas ressalta tanto aspectos de desenvolvimento pessoal quanto profissional, o que destaca as vantagens educacionais e profissionais deste tipo de experiência. (2) $^{(2)}$ Além disso, $100 \%$ dos alunos mencionaram se sentir em vantagem em relação a seus colegas que não fizeram estágio rural. Da mesma forma, $100 \%$ dos estudantes referiram que recomendariam o estágio a colegas.

Do ponto de vista dos professores, há mais vantagens do que desvantagens para os alunos em realizar um estágio no interior. As respostas podem ser vistas de forma geral na Tabela 7. Alguns dos tópicos apresentados já foram discutidos, e é interessante analisar a concordância de vários deles com o relato dos alunos. Entretanto, algumas ideias aparecem como novas, como a possibilidade de interação entre aluno e gestão e o relativo baixo status do professor generalista em área rural comparado com especialistas focais, que não aparecem na fala de alunos ou da equipe, como veremos a seguir.

Em relação ao primeiro item, é possível que a interação entre os alunos e a gestão seja pouco chamativa aos primeiros por diversos fatores, embora possa estar incluída na citação de contato com o sistema de saúde do interior. Outras explicações para este fato podem ser o pouco interesse dos mesmos nesta área, a preocupação com o aprendizado do trabalho mais especificamente médico, tendo em vista a proximidade da conclusão de sua formação e as provas de residência médica e a pequena ênfase direta e com tempo exclusivo para este tipo de atividade durante o estágio, ficando estas atividades predominantemente subentendidas e contando com influência indireta no dia a dia do estágio.

No que diz respeito ao status do professor, citado apenas por um professor, isto pode estar relacionado à insegurança pessoal do profissional $\mathrm{e}$ a aspectos culturais que valorizam diferentemente as áreas da medicina. Pode ser um fator importante, principalmente nos primeiros dias de estágio, relacionados a preconceitos em relação à qualidade do trabalho em saúde rural e urbano, mas não parece se sustentar, visto que ao final do estágio aparecem com frequência como pontos positivos citados pelos alunos a qualidade da atenção e a relação com os professores. Embora isso seja assim, o ponto mencionado pelo professor pode espelhar o esforço necessário para estes profissionais em desfazer certas pré-concepções dos alunos. Esta avaliação é parcialmente derivada de dados das entrevistas com os professores e que está em fase de análise e será publicada futuramente.

Tabela 7 - Vantagens e desvantagens destacadas pelos professores, em relação à educação médica rural.

\begin{tabular}{ll}
\hline Aspectos positivos & Aspectos negativos \\
\hline $\begin{array}{l}\text { Vivência da realidade local (problemas e recursos disponíveis; } \\
\text { contato com pacientes) }(\mathrm{n}=4) .\end{array}$ & $\begin{array}{l}\text { Número de problemas de saúde relativamente } \\
\text { limitado àquela comunidade }(\mathrm{n}=1) . \\
\text { Responsabilização e autonomia do aluno }(\mathrm{n}=2) .\end{array}$ \\
$\begin{array}{l}\text { Dificuldade de acesso }(\mathrm{n}=1) . \\
\text { Prática médica resolutiva e percepção disso pelo aluno }(\mathrm{n}=2) .\end{array}$ \\
$\begin{array}{l}\text { Qualidade de vidatus do professor perante especialistas } \\
\text { focais }(\mathrm{n}=1) .\end{array}$ \\
$\begin{array}{l}\text { Contato com a equipe de saúde ( } \mathrm{n}=1) . \\
\text { Prática de medicina reflexiva, centrada na pessoa }(\mathrm{n}=1) .\end{array}$ \\
$\begin{array}{l}\text { Melhor percepção do impacto da APS em uma comunidade }(\mathrm{n}=1) . \\
\text { Possibilidade de interagir com a gestão }(\mathrm{n}=1) .\end{array}$ \\
Relacionamento diferenciado com o professor $(\mathrm{n}=1)$.
\end{tabular}

Fonte: os autores. 


\section{Resultados dos questionários da equipe}

Embora o contato com equipes de saúde seja citado como um dos pontos positivos da formação na comunidade, ${ }^{(51)}$ raramente se avaliam estas experiências do ponto de vista das mesmas equipes. ${ }^{(52)}$ A seguir, apresentaremos uma avaliação global da experiência de ensino a partir do ponto de vista de membros da equipe de saúde do Pinhal Alto, no município de Nova Petrópolis, a que recebe alunos há mais tempo. Esta avaliação se dará a partir do que a equipe julga positivo e/ou negativo para os pacientes/usuários, para os alunos e para os próprios membros da equipe.

Quanto aos pacientes, a qualidade do atendimento foi o item mais citado. Para alguns dos trabalhadores ela resulta de uma postura de maior receptividade dos estudantes. Para outros, ela está relacionada a um maior tempo das consultas, que contribui para a maior profundidade das mesmas, com maior tempo tanto para os pacientes explicarem seus problemas quanto para receberem informações mais detalhadas e claras. Ainda foi referido que, pelo fato de o estudante e o professor estarem mais atualizados por causa do contato acadêmico, produzir-se-ia um melhor resultado para o paciente. Isso também foi mencionado como positivo pela possibilidade de ser uma "segunda opinião" clínica. Também foram destacadas as ações educativas na comunidade, que são realizadas regularmente pelos estudantes, como vantajosas para a comunidade.

Tabela 8 - Aspectos positivos e negativos para os pacientes, destacados por membros da equipe de saúde em relação ao estágio rural.

\section{Aspectos positivos}

Mais tempo para o diálogo entre médico

e paciente $(n=5)$.

Atendimento integral e por profissional atualizado $(\mathrm{n}=2)$.

Intervenções comunitárias $(\mathrm{n}=2)$.

Postura atenciosa e receptiva do estudante $(n=1)$.

Segunda opinião na consulta $(\mathrm{n}=1)$.

\section{Aspectos negativos}

Demora na consulta $(n=7)$.

Relatar problemas para desconhecidos $(n=1)$.

Alta rotatividade de estudantes $(n=1)$.

Dúvidas em relação à experiência do estudante $(\mathrm{n}=1)$.

Fonte: os autores.

É interessante observar que, apesar de muito citada como vantagem para os pacientes, a duração da consulta também aparece nas respostas como a maior dificuldade e como motivo de reclamação. Seguem-se a insegurança em relação à experiência do atendente, a troca frequente de estudantes e o desconforto de relatar seus problemas a um desconhecido, com uma citação cada (Tabela 8).

Em relação aos alunos, a equipe cita mais frequentemente pontos positivos do que negativos (ver Tabela 9). Metade dos profissionais não soube apontar nenhum ponto negativo e os que o fizeram destacaram a distância a percorrer e as dificuldades de comunicação, em especial pela língua alemã. Em relação aos pontos positivos, estão a aquisição de experiência, conhecimento da realidade rural, treinamento de habilidades e conhecimentos. É interessante notar como vários membros da equipe destacam a integralidade do atendimento como ponto forte, citando que o aluno tem contato com uma grande variedade de problemas e fases do ciclo vital, bem como complexidade cultural. 
Tabela 9 - Aspectos positivos e negativos para os alunos, destacados por membros da equipe de saúde em relação ao estágio rural.

\begin{tabular}{ll}
\hline Aspectos positivos & Aspectos negativos \\
\hline $\begin{array}{l}\text { Experiência do rural em si }(\mathrm{n}=4) . \\
\text { Experiência em medicina rural }(\mathrm{n}=4) \text { incluindo treinamento } \\
\text { de habilidades, integralidade da atenção e competência cultural. } \\
\text { Motivação geral }(\mathrm{n}=1) .\end{array}$ & $\begin{array}{l}\text { Deslocamento e distâncias }(\mathrm{n}=3) . \\
\text { Não relatou nenhum }(\mathrm{n}=4) .\end{array}$ \\
\hline
\end{tabular}

Fonte: os autores.

Em relação à equipe, os pontos positivos citados foram a colaboração nas atividades da equipe e a contribuição nas atividades de educação permanente (Tabela 10). A demora nas consultas foi novamente citada neste item como negativa, em alguns casos pelas reclamações a membros da equipe. Este problema aparece na literatura também em outros países, como fator de alguma resistência à presença de estudantes. ${ }^{(48,53)}$ A divisão do (pouco) espaço da unidade e o relacionamento de algumas duplas de estudantes foram citados também. Interessante notar que houve divisão de opinião em relação ao número de consultas, com um profissional apontando um aumento como ponto positivo e outro referindo que o fato de ter estudantes diminui o número de atendimentos. De forma objetiva, estas impressões não se confirmam, visto que o número de atendimentos nesta unidade não é significativamente alterado pela presença de alunos, seguindo eles a agenda original do médico da unidade - com atendimentos previstos a cada quinze minutos - e conforme o modelo de consultas paralelas descrito na literatura. ${ }^{(2)}$ Neste modelo, o estudante tem seu próprio consultório e inicia o atendimento, sendo a seguir introduzida a figura do preceptor que revisa o trabalho feito e ajuda na tomada de decisões, assegurando a qualidade e concluindo a consulta. Desde que este modelo começou a ser implantado as observações de demora em tempo de consulta diminuíram consideravelmente entre os pacientes.

Tabela 10 - Aspectos positivos e negativos para a equipe, destacados por membros da equipe de saúde em relação ao estágio rural. EPS = Educação Permanente em Saúde.

\begin{tabular}{ll} 
Aspectos positivos & Aspectos negativos \\
\hline Colaborar com ações em equipe $(\mathrm{n}=3)$. & Divisão de espaço $(\mathrm{n}=2)$. \\
Colaborar com a EPS $(\mathrm{n}=3)$. & Demora para consultas $(\mathrm{n}=3)$. \\
Aumento na oferta de atendimentos $(\mathrm{n}=1)$. & Diminuição na oferta de atendimentos $(\mathrm{n}=1)$. \\
Troca de experiência em geral $(\mathrm{n}=1)$. & Não respondeu $(\mathrm{n}=1)$. \\
& Falta interação com equipe de alguns estudantes $(\mathrm{n}=1)$.
\end{tabular}

Fonte: os autores.

A complementaridade de pontos de vista dos alunos, professores e equipe de saúde é importante, visto que se percebe o surgimento de novas informações a cada grupo incluído. Uma etapa de avaliação do ponto de vista dos usuários das unidades parceiras parece impor-se como etapa futura, tendo sido inicialmente prevista, mas abandonada devido às mudanças de rotina impostas pela pandemia de Covid-19. Há visivelmente necessidade de buscarse o equilíbrio entre as necessidades de todos os envolvidos, ficando evidente como não há apenas benefícios, mas também custos para os envolvidos. 
Isso pode ser facilitado pela participação de todos (comunidade, gestão, equipe e universidade) desde o início dos projetos. O envolvimento ativo dos estudantes como parte das soluções e como agregadores de melhoramentos deve ser estimulado para a manutenção em longo prazo das experiências de ensino médico rural. ${ }^{(2)} \mathrm{O}$ engajamento nas atividades de educação permanente dos profissionais e em atividades com a comunidade para além dos atendimentos individuais, tais como projetos de planejamento e promoção em saúde, assim como o cuidado com o uso do tempo e do espaço no dia a dia, aparecem a partir destes resultados como importantes, a serem considerados para o sucesso das parcerias.

\section{Conclusão}

Este estudo aprofunda a avaliação de alguns aspectos do internato rural em Medicina de Família e Comunidade da Universidade de Caxias do Sul e seus resultados contribuem para a educação médica e políticas de recursos humanos em saúde. A partir da discussão dos resultados obtidos, podese concluir que a experiência de educação médica rural tem atingido bons resultados. Estes ocorrem em vários níveis, como o de chamar a atenção dos estudantes para outros cenários potenciais de trabalho futuro, o que é importante devido à escassez de profissionais de saúde em áreas rurais.

Embora a origem não urbana dos estudantes seja um fator importante no interesse pelo trabalho nas áreas rurais, o estágio parece ter um impacto significativo em alunos de áreas urbanas também, que são maioria. Estes achados reforçam a importância de adotarem-se múltiplas estratégias em diversas etapas da formação (e após), como sugerem as evidências internacionais de implementação de "itinerários rurais" ("rural pathways") de recrutamento e retenção.

Tais fatores devem ser equilibrados com os aspectos de qualidade de vida pessoal e familiar e melhoramento do sistema de saúde como um todo, visto que são aspectos mais frequentemente citados pelos alunos. Os motivadores para realização do estágio rural mencionados podem ser úteis para a criação e aprimoramento de experiências similares. $\mathrm{O}$ apoio institucional para os deslocamentos e estadia dos alunos, bem como o investimento em um corpo de professores com formação específica e inserção nas comunidades, destacam-se como essenciais para a qualidade da experiência. $\mathrm{O}$ diálogo entre as comunidades, equipes de saúde, universidade e gestores locais é essencial para a superação dos desafios cotidianos e para a manutenção das atividades.

Por fim, sugere-se que outros estudos para aprofundar estas experiências sejam realizados, avaliando diferentes durações e modelos de educação médica rural, o real impacto futuro no local de trabalho e especialização do egresso, assim como a inclusão de outras perspectivas avaliativas, como a dos usuários do sistema.

\section{Referências}

1 Veras RM, Feitosa CCM. Reflexões em torno das Diretrizes Curriculares Nacionais do curso de graduação em Medicina a partir da Política Nacional de Promoção da Saúde. Interface (Botucatu). 2019; 23(Supl 1):e170743. doi: https://doi.org/10.1590/Interface.170743

2 Chater AB, Rourke J, Couper ID, Strasser RP, Reid S, editors. WONCA Rural Medical Education Guidebook. World Organization of Family Doctors (WONCA): WONCA Working Party on Rural Practice; 2014.

3 Brasil. Lei no 8080, de 19 de setembro de 1990. Dispõe sobre as condições para a promoção, proteção e recuperação da saúde, a organização e o funcionamento dos serviços correspondentes e dá outras providências [Internet]. Diário Oficial da União. Brasília; 1990. [citado 2021 mar 10]. Disponível em: http://www.planalto.gov.br/ ccivil_03/leis/18080.htm

4 World Health Organization. WHO guideline on health workforce development, attraction, recruitment and retention in rural and remote areas [Internet]. Geneva: WHO; 2021. [cited 2021 Apr 17]. Available from: https://www.who.int/ publications/i/item/9789240024229 
5 Tesson G, Curran V, Pong R, Strasser R. Advances in rural medical education in three countries: Canada, the United States and Australia. Educ Health (Abingdon, England). 2005; 18(3):405-15. doi: 10.1080/1357628050 0289728 .

6 Worley P, Couper I, Strasser R, Graves L, Cummings BA, Woodman R, et al. A typology of longitudinal integrated clerkships. Med Educ. 2016; 50(9):922-32. doi: 10.1111/ medu. 13084.

7 Targa LV, Wynn-Jones J, Howe A, Anderson MIP, Lopes JMC, Lermen Junior $\mathrm{N}$, et al. Declaração de Gramado pela Saúde Rural nos países em desenvolvimento. Rev Bras Med Fam Comunidade. 2014; 9(32):292-4. doi: https://doi.org/10.5712/rbmfc9(32)982

8 Almeida MM, Floss M, Targa LV, Wynn-Jones $\mathrm{J}$, Chater AB. It is time for rural training in family medicine in Brazil! Rev Bras Med Fam Comunidade. 2018; 13 (40):1-4. doi: http:// dx.doi.org/10.5712/rbmfc13(40)1696

9 Brasil. Lei $\mathrm{n}^{\mathrm{o}} 12.871$ de 22 de outubro de 2013. Institui o programa mais médicos, altera as leis $\mathrm{n}^{\circ} 8.745$, de 9 de dezembro de 1993, e $\mathrm{n}^{\circ}$ 6.932, de 7 de julho de 1981, e dá outras providências [Internet]. 2013. [citado $2021 \mathrm{mar}$ 20]. Disponível em: http://www.planalto.gov. br/ccivil_03/_ato2011-2014/2013/lei/112871. $\mathrm{htm}$

10 Polignano MV, Melo EM, Nascimento LE, Santana AMP, Rodrigues Junior IA. Internato rural da faculdade de medicina da UFMG: 25 anos de integração docente-assistencial. Anais do $2^{\circ}$ Congresso Brasileiro de Extensão Universitária; 2004 set 12-15; Belo Horizonte, MG, Brasil. [citado 2021 mar 10]. Disponível em: https://www.ufmg.br/congrext/Educa/ Educa107.pdf

11 Silveira RP, Pinheiro R. Internato rural na Amazônia: aspectos históricos, contexto atual e principais desafios. Hist Ciênc SaúdeManguinhos. 2017; 24(2):371-90. doi: https:// doi.org/10.1590/S0104-5970201700020 0004
12 Targa LV, Santos ND, Schwalm F, Barros EF, La Porta VL, Toscani G, et al. Internato médico rural na Serra Gaúcha: a experiência da Universidade de Caxias do Sul. Semina: Ciênc Biol Saúde. 2021; 42(1):59-70. doi: 10.5433/1679-0367.2021v42n1p59.

13 Scheffer M, Cassenote A, Guerra A, Guilloux AGA, Brandão APD, Miotto BA, et al. Demografia médica no Brasil 2020. São Paulo, SP: FMUSP, CFM; 2020.

14 Lima MC, Cuadrado M, Horta TCG, Almeida M, Pinheiro A, Maia PCGGS, Melo CP, et al. Manifesto de Natal - por uma política afirmativa no recrutamento, formação, provimento, retenção e suporte para as médicas de família em contexto rural e remoto. Rev Bras Med Fam Comunidade. 2016; 11(38):1-5. doi: https:// doi.org/10.5712/rbmfc11(38)1247

15 Wonca Working Party on Rural Practice. Policy on female family physicians in rural practice. Monash University School of Rural Health: Traralgon, Vic; 2002.

16 Rego RM, Marques NA, Monteiro PC, Oliveira CLB, Lins NAA, Caldas CAM. O perfil atual do estudante de Medicina e sua repercussão na vivência do curso. Pará Res Med J. 2018; 2(1-4):e05. doi: http://dx.doi.org/10.4322/ prmj.2018.005

17 Veras RM, Fernandez CC, Feitosa CCM, Fernandes S. Perfil socioeconômico e expectativa de carreira dos estudantes de medicina da Universidade Federal da Bahia. Rev Bras Educ Méd. 2020; 44(2):e056. doi: https://doi. org/10.1590/1981-5271v44.2-20190208

18 Cardoso Filho FAB, Magalhães JF, Silva KML, Pereira ISSD. Perfil do estudante de medicina da Universidade do Estado do Rio Grande do Norte (UERN), 2013. Rev Bras Educ Med. 2015; 39(1):32-40. doi: https://doi. org/10.1590/1981-52712015v39n1e01092014

19 Royston P, Mathieson K, Leafman J, Sheehan O. Medical student characteristics predictive of intent for rural practice. Rural Remote Health. 2012; 12(3):2107. doi: https://doi.org/ $10.22605 /$ RRH 2107 
20 Chan B, Degnai N, Critchton T, Pong RW, Rourke JT, Goertzen J, et al. Factors influencing family physicians to enter rural practice: does rural or urban background made a difference? Can Fam Physician [Internet]. 2005. [cited 2021 Apr 12]; 51(9): 1247-51. Available from: https://www.cfp.ca/content/cfp/51/9/1246.full. pdf

21 Walker JH, DeWitt DE, Pallant JF, Cunningham CE. Rural origin plus a rural clinical school placement is a significant predictor of medical students' intentions to practice rurally: a multiuniversity study. Rural Remote Health. 2012; 12(1):1908. doi: https://doi.org/10.22605/ RRH1908

22 Peña S, Ramirez J, Becerra C, Carabantes J, Arteaga O. The Chilean Rural Practitioner Programme: a multidimensional strategy to attract and retain doctors in rural areas. Bull World Health Organ. 2010; 88(5):371-8. doi: http://dx.doi.org/10.2471/BLT.09.072769

23 Pereyra-Elías R, Mayta-Tristán P, MontenegroIdrogo JJ, Mejia CR, Abudinén AG, AzucasPeralta $\mathrm{R}$, et al. Differences on primary care labor perceptions in medical students from 11 Latin American Countries. PLoS ONE 2016; 11(7):e0159147. https://doi.org/10.1371/ journal.pone. 0159147

24 Weber CAT. Dialectics of a medical provision policy in priority areas in Brazil. Rev Assoc Med Bras. 2017; 63(3):268-77. doi: 10.1590/18069282.63.03.268.

25 Baridon NO. Problems in rural surgery in Uruguay. World J Surg. 2006; 30(9):1634-5. doi: 10.1007/s00268-005-0642-4.

26 Pontillo AF, Torrealba MLV, Fuentes L. Percepción de las competencias adquiridas por los egresados de la escuela de medicina para el ejercicio como médico rural. Universidad de Carabobo, Nùcelo Valencia. Comunidad y Salud [Internet]. 2014. [citado 2021 abr 12]; 12(1):37-45. Disponible em: http://ve.scielo. org/pdf/cs/v12n1/art06.pdf

27 Mayta-Tristán P, Mejia CR, Riega-Lopez P, Rojas-Mezarina L, Posso M, Mezones-Holguín E. Proyección de trabajo en el interior del país y factores asociados en médicos recién colegiados de Lima, Perú 2010. Rev Peru Med Exp Salud Pública [Internet]. 2011. [citado $2021 \mathrm{abr}$ 17]; 28(2):186-93. Disponible em: http://www. scielo.org.pe/pdf/rins/v28n2/a04v28n2.pdf

28 Borracci R, Arribalzaga EB, Couto JL, Dvorkin M, Guerrero RA, Fernandez C, et al. Factors affecting willingness to practice medicine in underserved areas: a survey of Argentine medical students. Rural Remote Health. 2015; 15(4):3485. doi: https://doi.org/10.22605/ RRH3485

29 Tarqui-Mamani CB, Sanabria Rojas HA, Zárate Cárdenas E. Expectativas de laborar en el primer nivel de atención de salud de los estudiantes de una facultad de medicina de Lima, Perú. An Fac Med. 2015; 76(1):57-62. doi http://dx.doi.org/10.15381/anales.v76i1.11076

30 Huicho L, Molina C, Diez-Canseco F, Lema C, Miranda JJ, Huayanay-Espinoza CA, et al. Factors behind job preferences of Peruvian medical, nursing and midwifery students: a qualitative study focused on rural deployment. Hum Resour Health. 2015; 13(1):90. doi: 10.1186/s12960-015-0091-6

31 Ramírez M. Expectativas profesionales de internos de medicina y su inclinación por la atención primaria de salud. An Fac Med [Internet]. 2008. [citado 2021 mar 10]; 69(3):176-81. Disponível em: http://www.scielo.org.pe/pdf/ afm/v69n3/a06v69n3.pdf

32 Hogenbirk JC, Mian O, Pong RW. Postgraduate specialty training in northeastern Ontario and subsequent practice location. Rural Remote Health. 2011; 11(2):1603. doi: https://doi. org/10.22605/RRH1603

33 Wilson NW, Couper ID, De Vries E, Reid S, Fish T, Marais BJ. A critical review of interventions to redress the inequitable distribution of healthcare professionals to rural and remote areas. Rural Remote Health. 2009; 9(2):1060. doi: https://doi.org/10.22605/RRH1060

34 Williamson MI, Wilson R, McKechnie RC, Ross J. Does the positive influence of an undergraduate rural placement persist into 
postgraduate years? Rural Remote Health. 2012;12: 2011. doi: https://doi.org/10.22605/ RRH2011

35 O'Sullivan BG, McGrail MR, Russell D, Chambers H, Major L. A review of characteristics and outcomes of Australia's undergraduate medical education rural immersion programs. Human Resour Health. 2018; 16(1):8. doi: https://doi.org/10.1186/s12960-018-0271-2

36 Kapadia RK, McGrath BM. Medical school strategies to increase recruitment of ruraloriented physicians: the Canadian experience. Can J Rural Med [Internet]. 2011. [cited 2021 Apr]; 16(1):13. Available from: https://srpc.ca/ resources/Documents/CJRM/vol16n1/pg13. pdf

37 Hancock C, Steinbach A, Nesbitt TS, Adler SR, Auerswald CL. Why doctors choose small towns: a developmental model of rural physician recruitment and retention. Soc Sci Med. 2009; 69(9):1368-76. doi: 10.1016/j.socscimed. 2009.08.002.

38 Orzanco MG, Lovato C, Bates J, Slade S, Grand'Maison P, Vanasse A. Nature and nurture in the family physician's choice of practice location. Rural Remote Health. 2011; 11(3):1849. doi: https://doi.org/10.22605/RRH1849

39 Holst J, Normann O, Herrmann M. Strengthening training in rural practice in Germany: new approach for undergraduate medical curriculum towards sustaining rural health care. Rural Remote Health. 2015; 15(4):3563. doi: https://doi.org/10.22605/RRH3563

40 Matsumoto M, Inoue K, Kashima S, Takeuchi K. Does the insufficient supply of physicians worsen their urban-rural distribution? A HiroshimaNagasaki comparison. Rural Remote Health. 2021; 12(2):228. doi: https://doi.org/10.22605/ RRH2085

41 Saini NK, Sharma R, Roy R, Verma R. What impedes working in rural areas? A study of aspiring doctors in the National Capital Region, India. Rural Remote Health. 2021; 12(1):242. doi: https://doi.org/10.22605/RRH1967
42 Escalante-Romero L, Cueva-Chaves L, Linares Reyes E, Blossiers-Mazzini C. Experiencias de trabajo en actividades en Atención Primaria de Salud realizadas por estudiantes de medicina de Peru. Cienc Investig Méd Estud Latinoam [Internet]. 2010. [citado 2021 mar 10]; 15(1):148. Disponible en: https://www.cimel.felsocem. net/index.php/CIMEL/article/view/68/51

43 Sánchez Del Hierro G, Remmen R, Hendrickx $\mathrm{K}$. We need better medical undergraduate education in Ecuador. The case of perinatal mortality. Aten Primaria. 2017; 49(3):195-6. doi: 10.1016/j.aprim.2015.11.009.

44 Millán K, Vargas C, Madrid CN. Internado rural en la carrera de medicina de la Universidad de Chile; una experiencia de aprendizaje significativo. Educ Med [Internet]. 2006 [citado 2021 mar 05]; 9(3):20-1. Disponible em: https:// scielo.isciii.es/pdf/edu/v9n3/original3.pdf

45 Ruiz DG, Farenzena GJ, Haeffner LSB. Internato regional e formação médica: percepção da primeira turma pós-reforma curricular. Rev Bras Educ Méd. 2010; 34(1):21-7. doi: https:// doi.org/10.1590/S0100-55022010000100004

46 Stagg P, Prideaux D, Greenhill J, Sweet L. Are medical students influenced by preceptors in making career choices, and if so how? A systematic review. Rural Remote Health. 2012; 12(1):1832. doi: https://doi.org/10.22605/ RRH1832

47 Targa LV. Medicina de família e comunidade em cenários específicos: área rural. In: Gusso G, Lopes JMC. Tratado de medicina de família e comunidade: princípios, formação e prática. Porto Alegre: Artes Médicas; 2018. p. 498-507.

48 Price R, Spencer J, Walker J. Does the presence of medical students affect quality in general practice consultations? Med Educ. 2008; 42(4):374-381. doi: 10.1111/j.1365-2923.2008. 03016.x

49 Strasser R, Strasser S. Reimaging primary health care workforce in rural and underserved settings. Health, nutrition and population: discussion paper [Internet]. World Bank, 
Washington, DC; 2020. [cited 2021 Apr 10]. Available from: https://openknowledge. worldbank.org/handle/10986/34906

50 McWhinney IR, Freeman T. Manual de medicina de família e comunidade. Porto Alegre: Artes Médicas; 2010.

51 Dubé T, Schinke R, Strasser R. It takes a community to train a future physician: social support experienced by medical students during a community-engaged longitudinal integrated clerkship. Can Med Educ J [Internet]. 2019. [cited 2021 Mar 10]; 10(3):e5-e16. Available from: https://www.ncbi.nlm.nih.gov/pme/ articles/PMC6681930/pdf/CMEJ-10-e005.pdf

52 Morrison T, Brown J, Bryant M, Nestel D. Benefits and challenges of multi-level learner rural general practices - an interview study with learners, staff and patients. BMC Med Educ. 2014; 14(234):1-12. doi: 10.1186/14726920-14-234.

53 O’Flynn N, Spencer J, Jones R. Does teaching during a general practice consultation affect patient care? Br J Gen Pract [Internet]. 1999. [cited 2021 Mar 20]; 49(438):7-9. Available from: https://www.ncbi.nlm.nih.gov/pme/ articles/PMC1313309/pdf/10622008.pdf 


\section{Anexo 1 \\ Questionário autoaplicado pelos alunos}

Sexo: (M) (F) Idade:

Fez estágio rural: sim ( ) não ( )

1 - Onde você nasceu (escolha a opção que considera mais adequada)?

a) Área predominantemente rural remota

b) Área predominantemente rural próxima a uma cidade

c) Área intermediária remota

d) Área intermediária próxima a uma cidade

e) Área predominantemente urbana

2 - Onde você estudou a maior parte de sua formação básica e média $\left(1^{\circ}\right.$ e $2^{\circ}$ graus escolares ou equivalente)?

a) Área predominantemente rural remota

b) Área predominantemente rural próxima a uma cidade

c) Área intermediária remota

d) Área intermediária próxima a uma cidade

e) Área predominantemente urbana

3 - Quando você foi aprovado para o curso de Medicina, como você classificaria a sua vontade de trabalhar como médico fora de uma grande cidade?

a) Altíssima (era seu plano preferencial)

b) Alta (pensava, mas não estava certo; ou era plano secundário)

c) Média (pensava como última opção)

d) Baixa (não gostaria; ou pensava negativamente em relação à opção)

e) Baixíssima (não pensou, ou pensava muito negativamente)

4 - Hoje em dia, como você considera a sua vontade de trabalhar fora de uma grande cidade?

a) Altíssima (era seu plano preferencial)

b) Alta (pensava, mas não estava certo; ou era plano secundário)

c) Média (pensava como última opção)

d) Baixa (não gostaria; ou pensava negativamente em relação à opção)

e) Baixíssima (não pensou, ou pensava muito negativamente)

5 - Se você fosse hoje trabalhar fora de uma grande cidade, qual seria o principal motivo?

6 - Qual a principal razão que o levaria a preferir trabalhar em uma grande cidade?

7 - Por que você escolheu fazer (ou não fazer) o estágio rural?

8 - O que você gostou mais durante o estágio rural?

9 - O que você gostou menos?

10 - Você acha que a experiência beneficiou sua formação pessoal e profissional? Como e por quê?

11 - Você se sentiu em vantagem ou desvantagem em relação a seus colegas que não fizeram o estágio rural? Comente. 
12 - Você acha que ter uma experiência em saúde rural durante sua formação médica aumentou sua chance de trabalhar em uma área rural ou cidade pequena? Justifique, se quiser.

13 - Você recomendaria o estágio rural para futuros internos?

a) $\operatorname{sim}$

b) não

c) talvez ou indiferente

14 - Você se sentiu em vantagem ou desvantagem em relação aos colegas que fizeram estágio rural? Comente. (Ignore esta questão se você fez o estágio rural). 


\section{Anexo 2}

\section{Questionário autoaplicável para profissionais da equipe de saúde}

1 - Cite algo positivo para os pacientes em relação a ter estudantes de Medicina no seu local de trabalho.

2 - Cite algo negativo para os pacientes em relação a ter estudantes de Medicina no seu local de trabalho.

3 - Cite algo positivo para os alunos em relação a treinarem no seu local de trabalho.

4 - Cite algo negativo para os alunos em relação a treinarem no seu local de trabalho.

5 - Cite algo positivo para a equipe / você em relação a ter estudantes de Medicina no seu local de trabalho.

6 - Cite algo negativo para a equipe / você em relação a ter estudantes de Medicina no seu local de trabalho. 